\title{
IL-17A-associated IKK-a signaling induced TSLP production in epithelial cells of COPD patients
}

Giulia Anzalone', Giusy Daniela Albano', Angela Marina Montalbano', Loredana Riccobono', Anna Bonanno', Rosalia Gagliardo ${ }^{1}$, Fabio Bucchieri ${ }^{2}$, Roberto Marchese ${ }^{3}$, Monica Moscato ${ }^{1}$ and Mirella Profita ${ }^{1}$

\begin{abstract}
Thymic stromal lymphopoietin (TSLP) is a cytokine expressed in the epithelium, involved in the pathogenesis of chronic disease. IL-17A regulates airway inflammation, oxidative stress, and reduction of steroid sensitivity in chronic obstructive pulmonary disease (COPD). TSLP and IL-17A were measured in induced sputum supernatants (ISs) from healthy controls $(\mathrm{HC})$, healthy smokers (HS), and COPD patients by enzyme-linked immunosorbent assay. Human bronchial epithelial cell line (16HBE) and normal bronchial epithelial cells were stimulated with rhIL-17A or ISs from COPD patients to evaluate TSLP protein and mRNA expression. The effects of the depletion of IL-17A in ISS, an anticholinergic drug, and the silencing of inhibitor kappa kinase alpha (IKKa) on TSLP production were evaluated in 16HBE cells. Coimmunoprecipitation of acetyl-histone H3(Lys14)/IKKa was evaluated in 16HBE cells treated with rhIL17A and in the presence of the drug. TSLP and IL-17A levels were higher in ISs from COPD patients and HS compared with HC. TSLP protein and mRNA increased in 16HBE cells and in normal bronchial epithelial cells stimulated with ISs from COPD patients compared with ISs from HC and untreated cells. IKKa silencing reduced TSLP production in 16HBE cells stimulated with rhIL-17A and ISs from COPD patients. RhIL-17A increased the IKKa/acetyl-histone H3 immunoprecipitation in 16HBE cells. The anticholinergic drug affects TSLP protein and mRNA levels in bronchial epithelial cells treated with rhIL-17A or with ISs from COPD patients, and IKKa mediated acetyl-histone H3(Lys14). IL-17A/IKKa signaling induced the mechanism of chromatin remodeling associated with acetyl-histone H3(Lys14) and TSLP production in bronchial epithelial cells. Anticholinergic drugs might target TSLP derived from epithelial cells during the treatment of COPD.
\end{abstract}

\section{Introduction}

Chronic obstructive pulmonary disease (COPD) is characterized by airway inflammation and by a progressive airflow limitation usually caused by tobacco smoke $^{1}$. The inflammation in COPD subjects is often resistant to corticosteroid treatments, and currently, there are no safe and effective alternative anti-

Correspondence: Mirella Profita (profita@ibim.cnr.it)

${ }^{1}$ Institute of Biomedicine and Molecular Immunology "A. Monroy" (IBIM),

National Research Council of Italy (CNR), Palermo, Italy

${ }^{2}$ Dipartimento di Biomedicina sperimentale e Neuroscienze Cliniche (BioNec), University of Palermo, Palermo, Italy

Full list of author information is available at the end of the article. inflammatory treatments ${ }^{2}$. The regular use of $\beta 2$ adrenergic agonists and anticholinergic bronchodilators is recommended to maximize bronchodilation according to the current guidelines for the treatment of $\mathrm{COPD}^{3,4}$. Several studies provide perspectives on the use of muscarinic receptor antagonists for asthma and COPD, as these drugs acutely affect cholinergic airways obstruction and may have important beneficial effects on $\beta_{2}$-agonist responsiveness, airway inflammation, and remodeling ${ }^{5}$. Many studies have proposed novel pharmacological strategies, including the use of anticholinergic drugs (Tiotropium) as anti-inflammatory and anti-remodeling drugs in $\mathrm{COPD}^{5-7}$.

\section{(0) The Author(s) 2018}

(c) (i) Open Access This article is licensed under a Creative Commons Attribution 4.0 International License, which permits use, sharing, adaptation, distribution and reproduction cc) in any medium or format, as long as you give appropriate credit to the original author(s) and the source, provide a link to the Creative Commons license, and indicate if changes were made. The images or other third party material in this article are included in the article's Creative Commons license, unless indicated otherwise in a credit line to the material. If material is not included in the article's Creative Commons license and your intended use is not permitted by statutory regulation or exceeds the permitted use, you will need to obtain permission directly from the copyright holder. To view a copy of this license, visit http://creativecommons.org/licenses/by/4.0/. 
Cigarette smoke-induced oxidative stress and nuclear factor kappa B $(\mathrm{NF} \kappa \mathrm{B})$ activation decrease the antiinflammatory effects of corticosteroids in the airways of COPD subjects ${ }^{8,9}$. NFkB regulates the production and activity of cytokines and chemokines associated with airway inflammation ${ }^{10}$. It is activated by phosphorylation, and the degradation of inhibitor kappa B (ІкB) by ІкB kinases (inhibitor kappa kinase alpha (IKK $\alpha$ ) and IKK $\beta$ ) leads to the nuclear translocation of $\mathrm{NFKB}$ and the transcription of NFKB-dependent genes ${ }^{11}$. IL-17A is a potent inducer of IL-8, a chemokine with a key role in the persistence of airway inflammation and in the reduction of steroid sensitivity, thereby exerting its action on human bronchial epithelial cells ${ }^{12,13}$.

Thymic stromal lymphopoietin (TSLP) is a cytokine of the IL-7 family produced mainly by stromal cells, including mast cells, and is involved in the activation, expansion, and survival of $\mathrm{T}$ lymphocytes and dendritic cells $^{14,15}$. Its action is mediated by a heterodimeric receptor composed of IL-7R $\alpha$ and TSLP receptor (TSLPR) in allergies and asthma ${ }^{16}$. The epithelial-derived TSLP is important for the initiation of allergic airway inflammation through a dendritic cell-mediated $\mathrm{T}$ helper 2 response. TSLP gene expression is controlled by inflammatory mediators, such as IL- $1 \beta$ and TNF- $\alpha$, in a NFkBdependent manner in airway epithelial cells ${ }^{10}$. Higher levels of TSLP are found in the bronchial mucosa of asthma and COPD patients, suggesting its involvement in the function and mechanisms of airway diseases as a signature of a "Th2-favoring", besides as well as a "proallergic" cytokine ${ }^{17}$. An increased number of cells expressing TSLP mRNA are has been reported in the bronchi of patients with stable COPD and control smokers with normal lung function, suggesting additional roles for TSLP in COPD immune pathogenesis ${ }^{18}$. Airway structural cells produce and are targets of TSLP, suggesting a potential autocrine loop that may have a profound effect on the local inflammatory response and airway remodeling ${ }^{17}$. To our knowledge, no study has investigated the anti-inflammatory influence of anticholinergic drugs on the molecular mechanisms of IKK $\alpha$ activity in the control of IL-17A-mediated production of TSLP in bronchial epithelial cells.

We aimed to study the levels of TSLP and IL-17A present in the induced sputum supernatants (ISs) from COPD patients. Furthermore, we set up in vitro studies to investigate the potential role of rhIL-17A in chromatin remodeling and IKK-driven NFKB activation of TSLP gene transcription in bronchial epithelial cells during COPD pathogenesis. Finally, we analyzed the "in vitro" anti-inflammatory effects of anticholinergic drugs (generally used in the treatment of COPD as bronchodilators) on IL-17A-mediated TSLP production in bronchial epithelial cells.

\section{Materials and methods \\ Patients}

We recruited three groups of subjects: healthy asymptomatic non-smoking subjects with normal lung function (healthy controls; HC) $(n=10)$, symptomatic smokers with normal lung function (healthy smokers; HS) $(n=10)$, and smokers with COPD $(n=12)$. The diagnosis and severity assessment of COPD were defined and classified according to the criteria reported in the Global Initiative for Obstructive Lung Disease (GOLD) guidelines for COPD management $(\text { GOLD stage } \geq I)^{19}$. COPD subjects who experienced Exacerbations within 1 month of the study were excluded. Patients with COPD had a smoking history of 10 pack years or more.

All COPD patients were in a stable condition. COPD patients who had routine chest X-rays and computed tomographic scans showing obvious emphysema were excluded. All patients were characterized in terms of gender, age, smoking history, COPD symptoms, comorbidity, and treatment history. The exclusion criteria included the following: other systemic diseases, chronic bronchitis, chronic spontaneous sputum production, other lung diseases, upper and lower respiratory tract infections, treatment with glucocorticoids or anticholinergics within 3 months of the study and treatment with long-acting $\beta_{2}$ adrenergic agonists in the 15 days preceding the study.

The bronchodilator reversibility test was performed to exclude an asthmatic component. The increase in forced expiratory volume in the 1st second after salbutamol was lower than $12 \%$ and $200 \mathrm{ml}$ compared with basal values in all COPD subjects.

The local Ethics Committee approved the study, and informed consent was obtained from each participating subject.

\section{Sputum induction and processing}

Sputum induction and processing were performed according to the plug method. In brief, after the collection of the sputum, the selected plugs were processed with $4 \times$ $\mathrm{w} / \mathrm{v}$ of $0.1 \%$ dithiothreitol (DTT), with the subsequent addition of $4 \times \mathrm{w} / \mathrm{v}$ phosphate-buffered saline (PBS) (PBS $1 \times$; Gibco). The resulting suspension was vortexed for $30 \mathrm{~s}$ and then centrifuged at $1000 \mathrm{~g}$ for $20 \mathrm{~min}$. The ISs were then aspirated and frozen at $-80^{\circ} \mathrm{C}$ in separate aliquots for the subsequent biochemical analyses. The cells obtained from IS were then cytocentrifuged (Cytospin 2; Shandon, Runcorn, UK) and stained with May-Grunwald-Giemsa. To obtain differential cell counts, two independent investigators examined the slides blindly, counting at least 400 cells per slide.

\section{Measurement of TSLP and IL-17A}

The levels of TSLP and IL-17A were measured in ISs using commercially available enzyme-linked 
immunosorbent assay kits (R\&D Systems. Inc, MN, USA). The sensitivities of the kits were $9.87 \mathrm{pg} / \mathrm{ml}$ and $15 \mathrm{pg} / \mathrm{ml}$ for TSLP and IL-17A, respectively.

\section{Epithelial cell cultures}

The SV40 large $\mathrm{T}$ antigen-transformed human bronchial epithelial cell line (16HBE) cell line (16HBE) was used for these studies. $16 \mathrm{HBE}$ is a cell line that retains the differentiated morphology and functions of normal airway epithelial cells. The cells represent a clonal diploid $(2 n=$ 6) cell line isolated from human lung. $16 \mathrm{HBE}$ cells were cultured as adherent monolayers in Eagle's minimum essential medium (MEM) supplemented with $10 \%$ heatinactivated $\left(56^{\circ} \mathrm{C}, 30 \mathrm{~min}\right)$ fetal bovine serum (FBS), $1 \%$ MEM (non-essential amino acids, Euroclone), $2 \mathrm{mM} \mathrm{L-}$ glutamine and $250 \mu \mathrm{g} / \mathrm{ml}$ gentamicin at $37^{\circ} \mathrm{C}$ in a humidified $5 \% \mathrm{CO}_{2}$ atmosphere.

\section{Lung biopsy collection and processing}

Bronchoscopy with endobronchial biopsy was performed on six subjects. The biopsies were obtained from normal tissue. The tissue specimens obtained from bronchoscopic biopsy were placed in a tube with sterile Eagle's MEM supplemented with 10\% heat-inactivated $\left(56^{\circ} \mathrm{C}, 30 \mathrm{~min}\right.$ ) FBS, $1 \%$ MEM (non-essential amino acids, EuroClone), $2 \mathrm{mM}$ L-glutamine, $500 \mu \mathrm{g} / \mathrm{mL}$ gentamicin, and $50 \mathrm{mg} / \mathrm{mL}$ fungizone at $37^{\circ} \mathrm{C}$ in a humidified $5 \% \mathrm{CO} 2$ atmosphere overnight. The next day, the biopsy samples were cut into smaller sample sizes to facilitate the epithelial cell culture and then placed in bovine collagen I (Gibco, Waltham, MA USA) coated 60-mm tissue culture dishes containing bronchial epithelial growth medium (BEGM, Lonza, Wokingham, UK).

\section{Human primary bronchial epithelial cell culture}

The primary cells derived from bronchial tissue were successfully used to generate normal human bronchial epithelial cell cultures (NHBECs) after 6-7 days. When the epithelial cells reached $80-90 \%$ confluence, they were dissociated using trypsin-ethylenediaminetetraacetic acid (EDTA) and passaged onto collagen-coated plastic tissue culture plates (Corning Inc. Wilkes-Barre, PA) to be stimulated. Cells at passage (p) 1 or 2 were used for experimentation. Control experiments confirmed that there were no significant differences between the responses of the cells at passages $\mathrm{p} 1$ and $\mathrm{p} 2$.

\section{Bronchial epithelial cell stimulation}

$16 \mathrm{HBE}$ cells $(180,000$ cells/well) were plated in standard six-well culture plates in MEM 10\% FBS and grown to confluence (70-80\%). After $1 \mathrm{~h}$ in $1 \mathrm{ml}$ of MEM 1\% FBS, the $16 \mathrm{HBE}$ cells were stimulated with ISs $(20 \%)$ from HC $(n=6)$, HS $(n=6)$, and COPD $(n=6)$ subjects or with recombinant human (rh) IL-17A $(20 \mathrm{ng} / \mathrm{ml}) \quad(n=6)$.
Furthermore, ISs from COPD patients with the IL-17 concentrations closest to the median of the values were selected to stimulate $16 \mathrm{HBE}$. A total of $200 \mu \mathrm{l}$ of ISs was incubated with a rabbit polyclonal anti-human IL-17 antibody (H-132) (Santa Cruz Biotechnology, CA, USA) for $1 \mathrm{~h}$ at $37^{\circ} \mathrm{C}$ to neutralize the specific activity before the stimulation of $16 \mathrm{HBE}$ cells $(n=6)$. To determine the effects of anticholinergic bronchodilator compounds on IL-17A activity, tiotropium Spiriva ${ }^{\circledR}(100 \mathrm{nM})$ (Boehringer Ingelheim Pharma GmbH \& Co.KG, Biberach, Germany) was added to $16 \mathrm{HBE}$ cells and NHBECs for $30 \mathrm{~min}$ before the stimulation with ISs from COPD $(n=6)$ or with rhIL17A $(20 \mathrm{ng} / \mathrm{ml})(n=6) .16 \mathrm{HBE}$ were stimulated for $24 \mathrm{~h}$ for western blot and for $4 \mathrm{~h}$ to test for TSLP mRNA using real-time Polymerase chain reaction (PCR), IKK $\alpha$ coimmunoprecipitation and ChiP assay. Similar to the 16HBE cells, the NHBECs were cultured with rhIL-17A and with ISs from COPD patients to evaluate the TSLP expression by western blot analyses and real-time PCR.

\section{Total protein extraction}

16HBE cells were washed with cold PBS and lysed in a buffer containing $10 \mathrm{mmol} / \mathrm{L}$ Tris- $\mathrm{HCl}(\mathrm{pH}$ 7.4), 50 $\mathrm{mmol} / \mathrm{L} \mathrm{NaCl}, 5 \mathrm{mmol} / \mathrm{L}$ EDTA, and $1 \%$ Nonidet P-40. The phosphatase inhibitors included $20 \mathrm{mmol} / \mathrm{L} \beta$-glycerophosphate, $0.3 \mathrm{mmol} / \mathrm{L} \mathrm{Na}_{3} \mathrm{VO}_{4}$, and $1 \mathrm{mmol} / \mathrm{L}$ benzamidine (ICN Biochemicals, Inc, Aurora, OH, USA), and the protease inhibitors consisted of the complete protease inhibitor cocktail (Roche). The protein content of the supernatants was analyzed using the bicinchoninic acid assay (Pierce, Rockford, IL, USA); 25-30 $\mu \mathrm{g}$ of the lysate was then denatured under reducing conditions by boiling for $3 \mathrm{~min}$ in $50 \mathrm{mM}$ Tris-HCl (pH 6.8), $1 \%$ sodium dodecyl sulfate (SDS), $2 \% \beta$-mercaptoethanol, and $0.01 \%$ bromophenol blue. The total protein extracts were analyzed by western blot analysis.

The proteins were separated by SDS-polyacrylamide gel electrophoresis (PAGE) and transferred by electrophoresis onto Immobilon-P membranes (Millipore, Bedford, MA, USA). After the transfer, the membranes were blocked overnight at room temperature in PBS containing $3 \%$ bovine serum albumin and $0.5 \%$ Tween 20 and then incubated for $1 \mathrm{~h}$ at room temperature with the primary Abs. After washing, the blots were incubated for $45 \mathrm{~min}$ with the appropriate horseradish peroxidaseconjugated secondary $\mathrm{Ab}$, and the bound $\mathrm{Ab}$ was detected using the ECL chemiluminescence detection system (Amersham-Pharmacia, Biotech), according to the manufacturer's instructions. The membranes were stripped and reprobed with $\mathrm{Ab}$ against the housekeeping protein $\beta$-actin to normalize the differences in protein loading. Autoradiographic films were scanned and analyzed by densitometry using the NIH Image/Gel Plotting analysis program (National Institutes of Health, 
Bethesda, MD, USA). The results were normalized and expressed as ratios of the band intensities of the proteins and $\beta$-actin.

\section{Western blot antibodies}

The following antibodies were used: rabbit anti-human TSLP (ProSci, Ca, USA) diluted to a ratio of 1:100, rabbit polyclonal anti-human IKK $\alpha \mathrm{Ab}$, clone 14A23 (Millipore, $\mathrm{Ca}$, USA) diluted to 1:100; mouse monoclonal antihuman Ac-His H3 (Lys14) Ab, clone 13HH3-1A5 (Millipore, $\mathrm{Ca}$, USA) diluted to 1:100; and mouse monoclonal anti- $\beta$-actin Ab (Sigma, St. Louis, MO, USA) diluted to $1: 20,000$.

\section{Quantitative RT-PCR of TSLP}

Total RNA was extracted from 16HBE cells using the TRIzol Reagent (Invitrogen) following the manufacturer's instructions and reverse-transcribed into complementary DNA using M-MLV-RT and oligo $(\mathrm{dT})_{12-18}$ primers (Invitrogen). Quantitative real-time PCR of the TSLP transcript was conducted using the StepOne Plus Realtime PCR System (Applied Biosystems, Foster City, CA, USA) with specific FAM-labeled probes and primers (prevalidated TaqMan Gene expression assay for TSLP Hs00263639m1, Assays on Demand, Applied Biosystems). TSLP gene expression was normalized to that of the endogenous glyceraldehyde-3-phosphate dehydrogenase (GAPDH) control gene. The relative quantitation of gene expression was carried out using the comparative $C_{T}$ method $\left(2^{-\Delta \Delta \mathrm{Ct}}\right)$ and plotted as fold-change compared with to untreated cells as the reference sample.

\section{Silencing of IKKa}

To confirm the role of IKK $\alpha$ in the expression of TSLP, we investigated the effects of IKK $\alpha$ silencing in human bronchial epithelial cells using specific short interfering RNA (siRNA) transfection. 16HBE cells were plated on six-well tissue culture plates and grown in medium containing 10\% FBS without antibiotics until $60-80 \%$ confluence. IKK $\alpha$ siRNA $(10 \mu \mathrm{M}$; Santa Cruz Biotechnology, Inc.) was then added to $100 \mu \mathrm{l}$ of the siRNA transfection medium, and the reaction was performed according to the manufacturer's instructions until complete cell transfection was achieved $\left(7 \mathrm{~h}\right.$ at $\left.37^{\circ} \mathrm{C}\right)$. For optimal siRNA transfection efficiency, siRNA $(10 \mu \mathrm{M}$; Santa Cruz Biotechnology, Inc.) containing a scrambled sequence, which did not lead to the specific degradation of any known cellular mRNA, was used to control for the non-specific effects. Finally, the cells were stimulated with rhIL-17A or ISs from COPD (20\%) patients for $24 \mathrm{~h}$, and the total and nuclear proteins were extracted. The silencing efficacy of IKK $\alpha$ RNA interference using this method has been described in detail in a previous paper ${ }^{18}$.

\section{Co-immunoprecipitation}

$16 \mathrm{HBE}$ cells were washed with cold PBS $1 \times$ before being lysed in a mild protein lysis buffer $(50 \mathrm{mM}$ Tris- $\mathrm{HCl}, 150 \mathrm{mM} \mathrm{NaCl}, 10 \mathrm{mM}$ EDTA, and 0.1\% Nonidet P-40) containing protease and phosphatase inhibitors. The cell lysate was pre-cleaned with protein A agarose beads (Protein A/GPlus-Agarose, Santa Cruz Biotechnology, Santa Cruz, CA, USA) and subsequently incubated overnight with rabbit polyclonal anti-acetylhistone H3(Lys14) Ab (Millipore, CA, USA) (1:100) (pulldown). Protein A agarose beads were added and incubated for $1 \mathrm{~h}$ at $4{ }^{\circ} \mathrm{C}$. The immunoprecipitates (IPs) were washed and boiled in $2 \times$ SDS sample buffer for 5 min and centrifuged, and cell lysates were separated on 10\% SDS/ PAGE gels in preparation for western blotting with rabbit anti-human IKK $\alpha$ Ab. Non-immunized IgG was applied as the pull-down control to confirm the binding specificity. The total protein without IPs was run simultaneously as the control.

\section{ChiP assay}

Chromatin immunoprecipitation (ChiP) analysis was performed according to the manufacturer's instructions using the EZ-ChiP kit (UpstateBiotechnology, Inc., Lake Placid, NY, USA) in 16HBE cells. In brief, $37 \%$ paraformaldehyde was added to the culture medium to immobilize the DNA-protein and protein-protein interactions. Cells were washed twice with ice-cold PBS, resuspended in SDS cell lysis buffer containing protease inhibitor cocktail II, and kept in ice for $15 \mathrm{~min}$. Cell lysates were sonicated on ice until the cross-linked chromatin was sheared to yield DNA fragments between 200 and $1000 \mathrm{bp}$. Each immunoprecipitation sample was diluted 10 times with the ChIP dilution buffer containing protease inhibitor cocktail II. Protein G agarose (Santa Cruz Biotechnology, CA, USA) was added to each immunoprecipitated sample; $50 \%$ of the supernatants were incubated overnight at $4{ }^{\circ} \mathrm{C}$ with rabbit polyclonal anti-acetylhistone $\mathrm{H} 3$ (Lys14) Ab, and the other $50 \%$ were used as negative (normal mouse IgG, Millipore) and positive (anti-RNA polymerase II) controls. After the immunoprecipitation of the antibody/antigen/DNA complexes, the samples were eluted and subsequently treated with $\mathrm{NaCl} 5 \mathrm{M}$ at $65^{\circ} \mathrm{C}$ for $5 \mathrm{~h}$ to reverse the cross-linking of protein/DNA complexes and free DNA. DNA purification was performed using spin columns according to the manufacturer's instructions. PCR was performed with specific primers for 35 cycles, and amplified DNA fragments were analyzed on a $2 \%$ agarose gel by electrophoresis. PCR was performed using primers spanning the histone $\mathrm{H} 3$ binding site of the human TSLP gene promoter: 5'-GAGGGTCCAGAGCAATACAC-3' and primer: 5'TGGAAGgGatATCAGAGAGG-3'. Purified 
DNA immunoprecipitated for Polymerase II was then analyzed by PCR using specific control primers.

\section{Results}

\section{Demographic characteristics of patients and differential} cell counts of IS

The patient characteristics are summarized in Table 1. According to the differential cell counts of the IS samples, we observed an increase in the number of both macrophages and neutrophils in HS, whereas COPD subjects showed a higher increase in the number of neutrophils and fewer macrophages than HS and HC. A higher number of eosinophils was reported in COPD subjects than in $\mathrm{HC}$, whereas lymphocyte numbers did not differ between the three study groups (Table 2).

\section{Levels of TSLP and IL-17A in ISs}

TSLP concentrations were significantly higher in ISs from HS and COPD patients compared with ISs from HC $(p<0.001$ and $p<0.0001$, respectively) and in ISs from COPD patients compared with ISs from HS $(p<0.003)$ (Fig. 1a). Furthermore, IL-17A concentrations were significantly higher in ISs from COPD and HS than in those from $\mathrm{HC}(p<0.002$ and $p<0.05$, respectively) (Fig. 1b). Although the subjects used in this study are different, we obtained similar results to those previously observed ${ }^{20}$.

\section{TSLP production in 16HBE cells stimulated with rhIL-17A} and ISs from COPD patients

TSLP protein expression showed a significant increase in cell extracts from 16HBE cells stimulated with ISs from COPD patients compared with $16 \mathrm{HBE}$ cells stimulated with ISs from HC $(p<0.02)$ and untreated cells $(p<0.01)$ (Fig. 2). TSLP protein expression was significantly increased in cell extracts of $16 \mathrm{HBE}$ cells stimulated with rhIL-17A compared with untreated cells $(p<0.006)$. The

Table 1 Demographic characteristics of patients

\begin{tabular}{llll}
\hline & HC $(\boldsymbol{n}=\mathbf{1 0})$ & HS $(\boldsymbol{n}=\mathbf{1 0})$ & COPD $(\boldsymbol{n}=\mathbf{1 2})$ \\
\hline Age, year & $60 \pm 7$ & $61.5 \pm 8$ & $64 \pm 9$ \\
Gender, male/female & $6 / 4$ & $6 / 4$ & $7 / 5$ \\
FEV1, \% predicted & $102.6 \pm 12.6$ & $105.2 \pm 10$ & $60.7 \pm 14.5$ \\
FVC, \% predicted & $105.2 \pm 16.7$ & $109.1 \pm 15$ & $70.6 \pm 19.2$ \\
FEV1/FVC (\%) & $91.6 \pm 3.4$ & $89.3 \pm 4.9$ & $61.4 \pm 7.0$ \\
Smoking, pack/year & 0 & $60 \pm 18.0$ & $63 \pm 18.0$ \\
\hline
\end{tabular}

Data are presented as the mean $\pm \mathrm{SD}$. $H C$ healthy asymptomatic non-smoking subjects with normal lung function, $H S$ asymptomatic smokers with normal lung function, COPD subjects with chronic obstructive pulmonary disease, FEV1 forced expiratory volume in one second, FVC forced vital capacity
Table 2 Differential cell count of induced sputum samples

\begin{tabular}{llll}
\hline & HC $(\boldsymbol{n}=\mathbf{1 0})$ & HS $(\boldsymbol{n}=\mathbf{1 0})$ & COPD $(\boldsymbol{n}=\mathbf{1 2})$ \\
\hline Macrophages (\%) & 80 & 51.9 & 21.6 \\
& $(63.8-82.4)$ & $(47.1-68.1)$ & $(10.4-50.2)$ \\
Neutrophils (\%) & 17.2 & 46.1 & 71.8 \\
& $(8-22.1)$ & $(30.2-48.2)$ & $(38.2-82.5)$ \\
Lymphocytes (\%) & 0.2 & 0.7 & 1.4 \\
& $(0-0.8)$ & $(0.4-1.2)$ & $(0-1.3)$ \\
Eosinophils (\%) & 0.2 & 0.9 & 0.8 \\
& $(0-0.6)$ & $(0-1.4)$ & $(0.2-2.0)$ \\
Epithelial cells (\%) & 0.6 & 0.5 & 0.3 \\
& $(0.3-2)$ & $(0-0.8)$ & $(0-1.5)$ \\
\hline
\end{tabular}

Results are expressed as the median (25th to 75th percentiles). HC healthy asymptomatic non-smoking subjects with normal lung function, HS asymptomatic smokers with normal lung function, COPD subjects with chronic obstructive pulmonary disease

treatment of the cells with tiotropium significantly reduced TSLP production in $16 \mathrm{HBE}$ cells stimulated with rhIL-17A $(p<0.001)$ (Fig. 3a). The analysis of TSLP production in protein extracts of $16 \mathrm{HBE}$ cells stimulated with ISs from COPD patients showed a significant increase in comparison to untreated cells or to cells treated with DTT $(p<0.001$ and $p<0.02$, respectively). The increased production of TSLP protein induced by ISs was significantly reduced when the cells were treated with tiotropium $(p<0.003)$ or with ISs from COPD patients treated with anti-IL-17A Ab to deplete the IL-17A present in the samples $(p<0.053)$ (Fig. 3b). RT-PCR analysis of TSLP showed higher levels of mRNA expression in $16 \mathrm{HBE}$ cells stimulated with $20 \mathrm{ng} / \mathrm{ml}$ rhIL-17A compared with the untreated cells or 16HBE cells treated with tiotropium $(p<0.0003$ and $p<0.004$, respectively $)$ (Fig. 3c). Furthermore, 16HBE cells stimulated with ISs from COPD subjects showed a significant increase in TSLP mRNA expression (as indicated by the fewer amplification cycles required) compared with cells treated with DTT $(p<0.0001)$. 16HBE cells treated with tiotropium and $16 \mathrm{HBE}$ cells stimulated with ISs from COPD subjects treated with anti-IL-17A showed significantly lower levels of TSLP mRNA compared with cells stimulated with ISs from COPD patients $(p<0.0001$ and $p<$ 0.0001 , respectively) (Fig. $3 \mathrm{~d}$ ). Treatment with anti-IL$17 \mathrm{~A} \mathrm{Ab}$ or tiotropium alone did not affect TSLP protein or mRNA production (data not shown) in 16HBE cells. Because tiotropium is currently used in the pharmacological treatment of these patients as a bronchodilator, we tested its potential anti-inflammatory activity only in samples containing ISs from COPD subjects. 

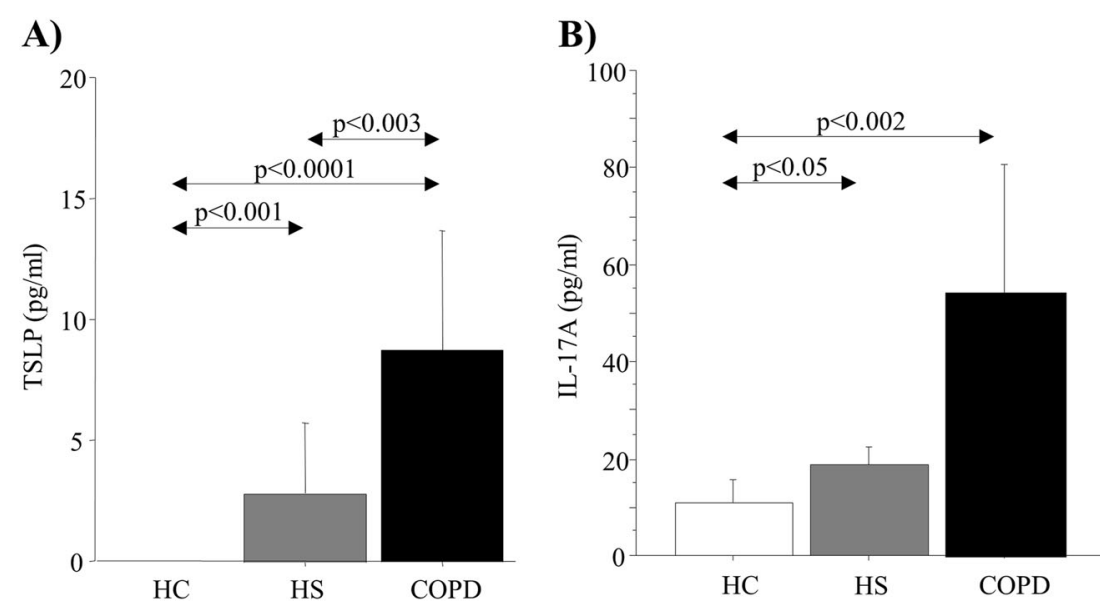

Fig. 1 TSLP and IL-17A concentrations in ISs from HC $(\boldsymbol{n}=\mathbf{1 0})$, HS $(\boldsymbol{n}=\mathbf{1 0})$, and COPD patients $(\boldsymbol{n}=\mathbf{1 2})$. a TSLP levels $(\mathrm{pg} / \mathrm{mL}) \mathrm{and} \mathbf{b} \mathrm{LL}-17 \mathrm{~A}$ levels ( $\mathrm{pg} / \mathrm{mL}$ ) were measured using specific commercially available kits as described in the "Materials and methods" section. Two technical replicates were performed. The bars represent the mean \pm SD of the values $(\mathrm{pg} / \mathrm{mL})$. Statistical analysis was performed using the Kruskal-Wallis test followed by Bonferroni-Dunn correction for multiple comparisons. A $p$ value $<0.05$ was considered statistically significant

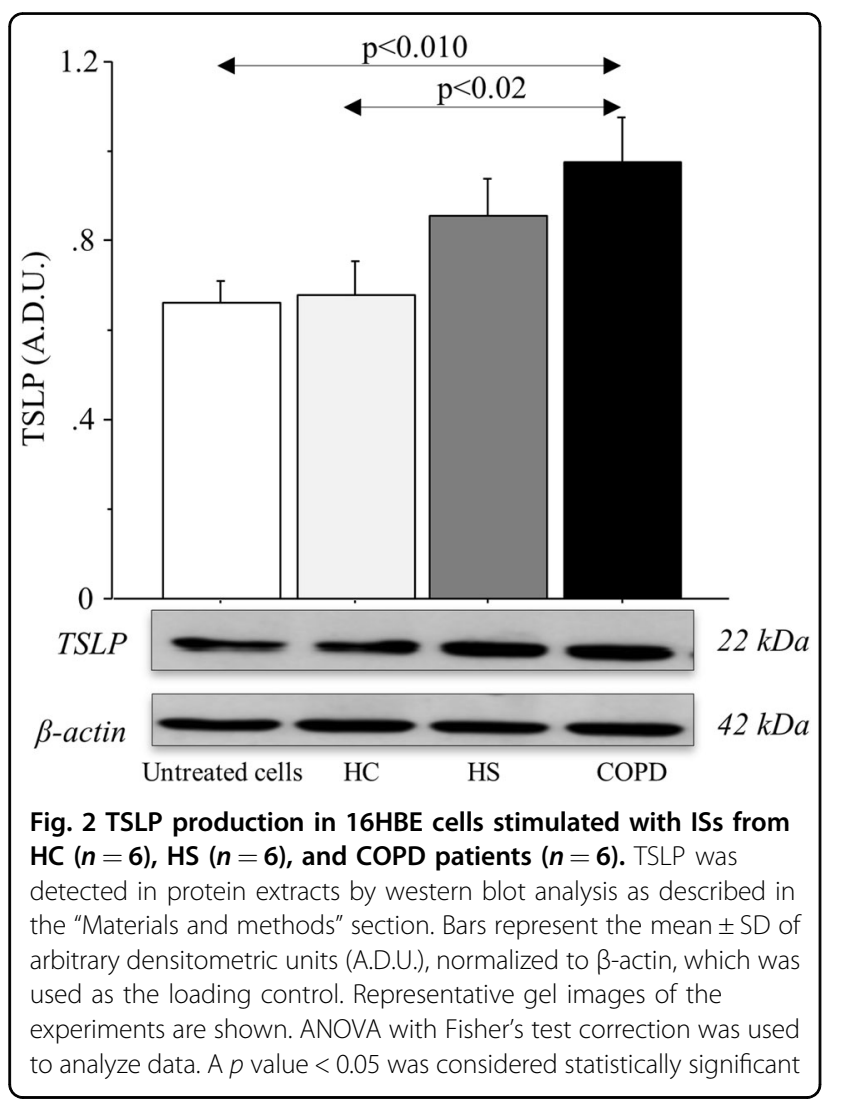

TSLP production in primary NHBE cells stimulated with rhIL-17A and ISs from COPD patients

TSLP protein expression was statistically higher in NHBECs stimulated with rhIL-17A compared with untreated cells $(p<0.004)$ and decreased following the treatment with tiotropium $(p<0.04)$ (Fig. 4a).
Furthermore, TSLP protein expression statistically increased when cells were stimulated with ISs from COPD patients compared with untreated cells $(p<0.005)$ and decreased following the treatment with tiotropium $(p<$ $0.003)$ or with ISs from COPD treated with anti-IL-17A $\mathrm{Ab}(p<0.001)$ (Fig. 4b). Real-time PCR analysis showed an increase in TSLP mRNA in NHBECs stimulated with ISs from COPD patients compared with untreated cells ( $p$ $<0.001$ ). Real-time PCR analysis showed an increase in TSLP mRNA in NHBECs stimulated with rhIL-17A compared with untreated cells $(p<0.004)$. Preincubation of NHBECs with tiotropium significantly reduced the effects of rhIL-17A on TSLP protein production $(p<0.001)$ (Fig. 4c). Finally, the pre-incubation of NHBECs with tiotropium or the treatment of ISs with anti-IL-17A Ab significantly reduced the effects of ISs from COPD $(p<0.001$ and $p<0.001$, respectively $)$ (Fig. 4d).

\section{Effect of IKKa silencing on TSLP expression}

The silencing efficacy of our RNA interference method for IKK $\alpha$ signaling was $40 \% \pm 3.6 \%$, as previously descri$\operatorname{bed}^{20}$. Temporary transfection of 16HBE cells with IKK $\alpha$ siRNA caused a statistically significant decrease of TSLP synthesis, as observed by western blot analysis. Particularly, the silencing of IKK $\alpha$ protein significantly decreased TSLP expression in untreated 16HBE cells $(p<0.01)$. Treating 16HBE cells with scrambled siRNA had no effect on the TSLP protein production compared with unsilenced cells $(p<0.01)$ (Fig. 5a). Finally, silencing the IKK $\alpha$ protein significantly decreased TSLP expression in cells stimulated with rhIL-17A $(p<0.001)$ (Fig. 5b) or in cells stimulated with ISs from COPD patients $(p<0.02)$ compared with unsilenced conditions (Fig. 5c). 


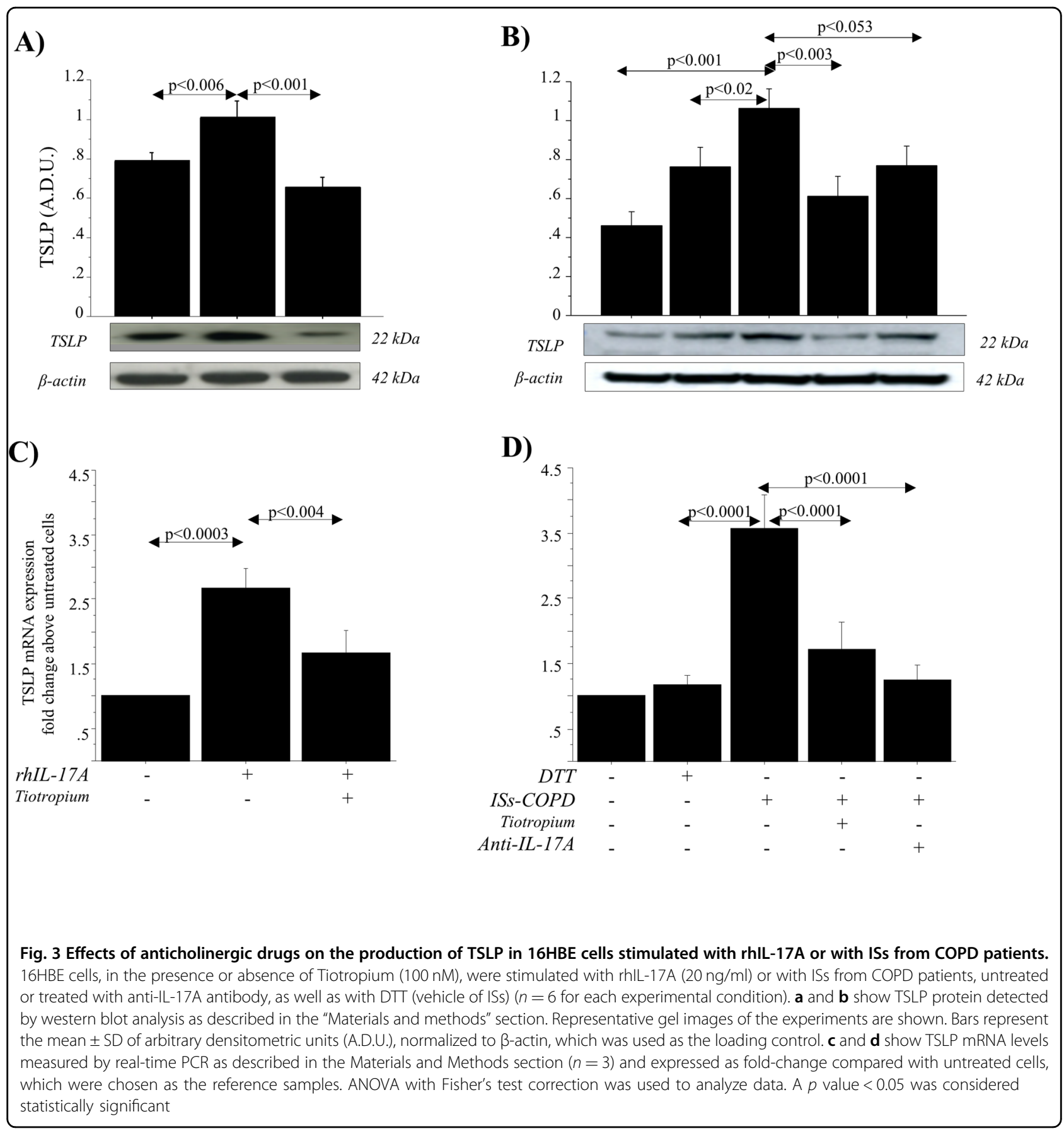

\section{Co-immunoprecipitation of acetyl-histone H3/IKKa}

The evaluation of the interactions between acetylhistone $\mathrm{H} 3$ and $\mathrm{IKK} \alpha$ proteins by coimmunoprecipitation showed that rhIL-17A $(20 \mathrm{ng} / \mathrm{ml})$ increased the cross-coupling between IKK $\alpha$ proteins and acetyl-histone H3 (Lys14). The treatment of cells with tiotropium significantly reduced the effect of rhIL-17A on the coimmunoprecipitation of IKK $\alpha$ proteins and acetyl-histone H3(Lys14) (Fig. 6a).
Effects of IL-17A and ISs from COPD patients on chromatin

ChIP assays showed higher levels of anti-acetyl-histone $\mathrm{H} 3$ (Lys14) Ab binding to the promoter region of TSLP in $16 \mathrm{HBE}$ cells stimulated with rhIL-17A (20 ng/ml) (Fig. 6b) or with ISs from COPD patients compared with untreated cells (Fig. 6b and c). Furthermore, we showed that the pretreatment of cells with tiotropium or ISs from COPD patients treated with the anti-IL-17A Ab generated a band with lower levels of intensity in the TSLP promoter 


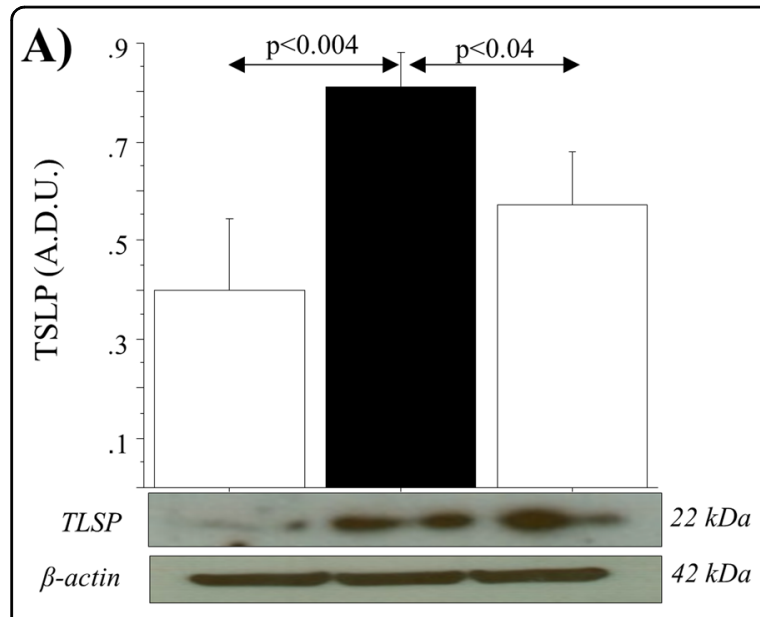

C)

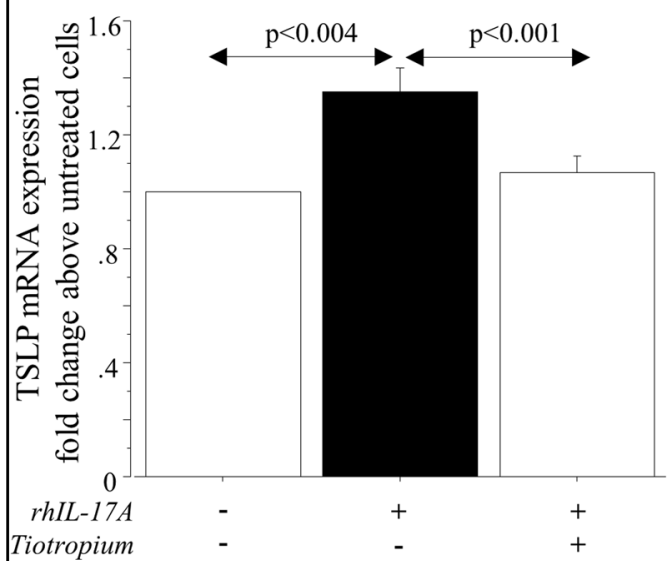

B)

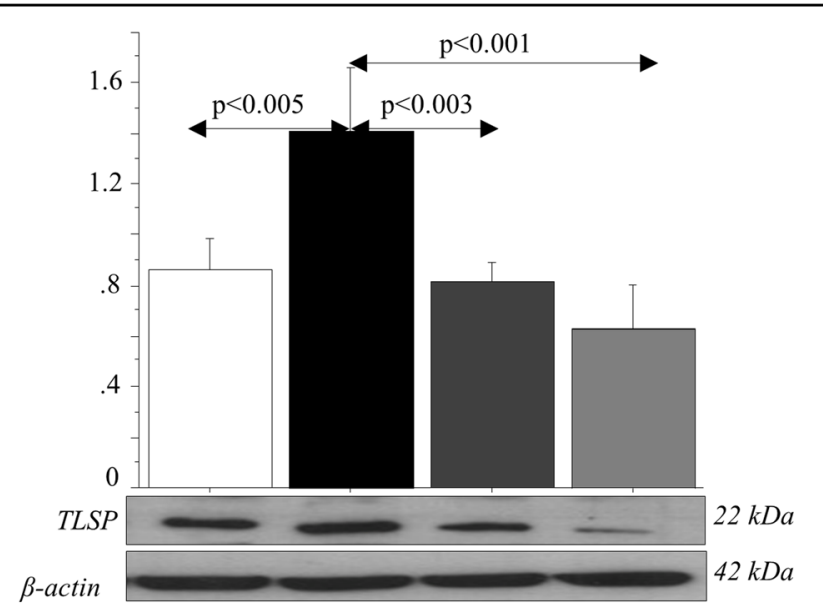

D)

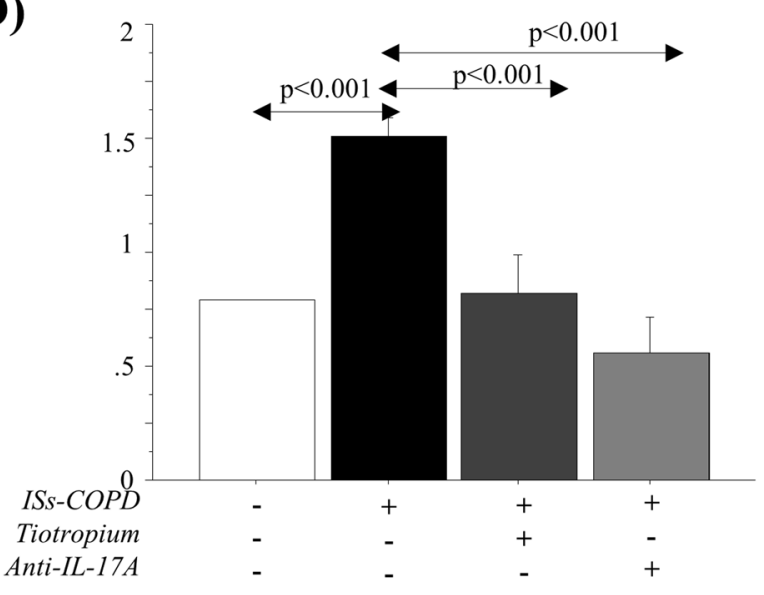

Fig. 4 Effect of anticholinergic drugs on TSLP production in NHBE cells stimulated with rhIL-17A or with ISs from COPD patients. NHBE cells, in the presence or absence of Tiotropium $(100 \mathrm{nM})$, were stimulated with rhIL-17A ( $20 \mathrm{ng} / \mathrm{ml})(n=3)$ or with ISs from COPD patients untreated or treated with anti-IL-17A antibody $(n=3)$ for each experimental condition). $\mathbf{a}$ and $\mathbf{b}$ show TSLP protein detected by western blot analysis as described in the "Materials and methods" section. Representative gel images of the experiments are shown. Bars represent the mean \pm SD of arbitrary densitometric units (A.D.U.), normalized to $\beta$-actin used as the loading control. $\mathbf{c}$ and $\mathbf{d}$ show TSLP mRNA levels measured by real-time PCR as described in the "Materials and Methods" section and expressed as fold-change compared with untreated cells, chosen as the reference sample. ANOVA with Fisher's test correction was used to analyze data. A $p$ value $<0.05$ was considered statistically significant

region compared with cells stimulated with rhIL-17A or ISs alone.

\section{Discussion}

In this study, we described the immunological link between IL-17A and TSLP levels observed in ISs from COPD patients. After studying the IL-17A and TSLP levels in COPD patients, we set up an "in vitro" model using 16HBE and NHBEC cells to illustrate how rhIL-17A or IL-17A found in the ISs from COPD subjects are involved in the production of TSLP in the airways. Furthermore, we described the molecular mechanisms of chromatin remodeling, associated with IL-17A-mediated
IKK $\alpha$ activity and histone $\mathrm{H} 3$ acetylation in Lys14, which lead to an increase in TSLP mRNA transcription in bronchial epithelial cells. Finally, we provided new pharmacological perspectives on the anti-inflammatory role of anticholinergic drugs in the treatment of COPD patients and described their ability to attenuate IL-17A-mediated TSLP production (Fig. 7).

Epithelial cells are involved in the regulation of lung fluid balance, metabolism, clearance of inhaled agents, and secretion of mediators, most of which recruit and activate inflammatory cells in response to injuries in the airway $^{21,22}$. Various invasive agents transduce the biological signals via an increase in the number of receptors in 


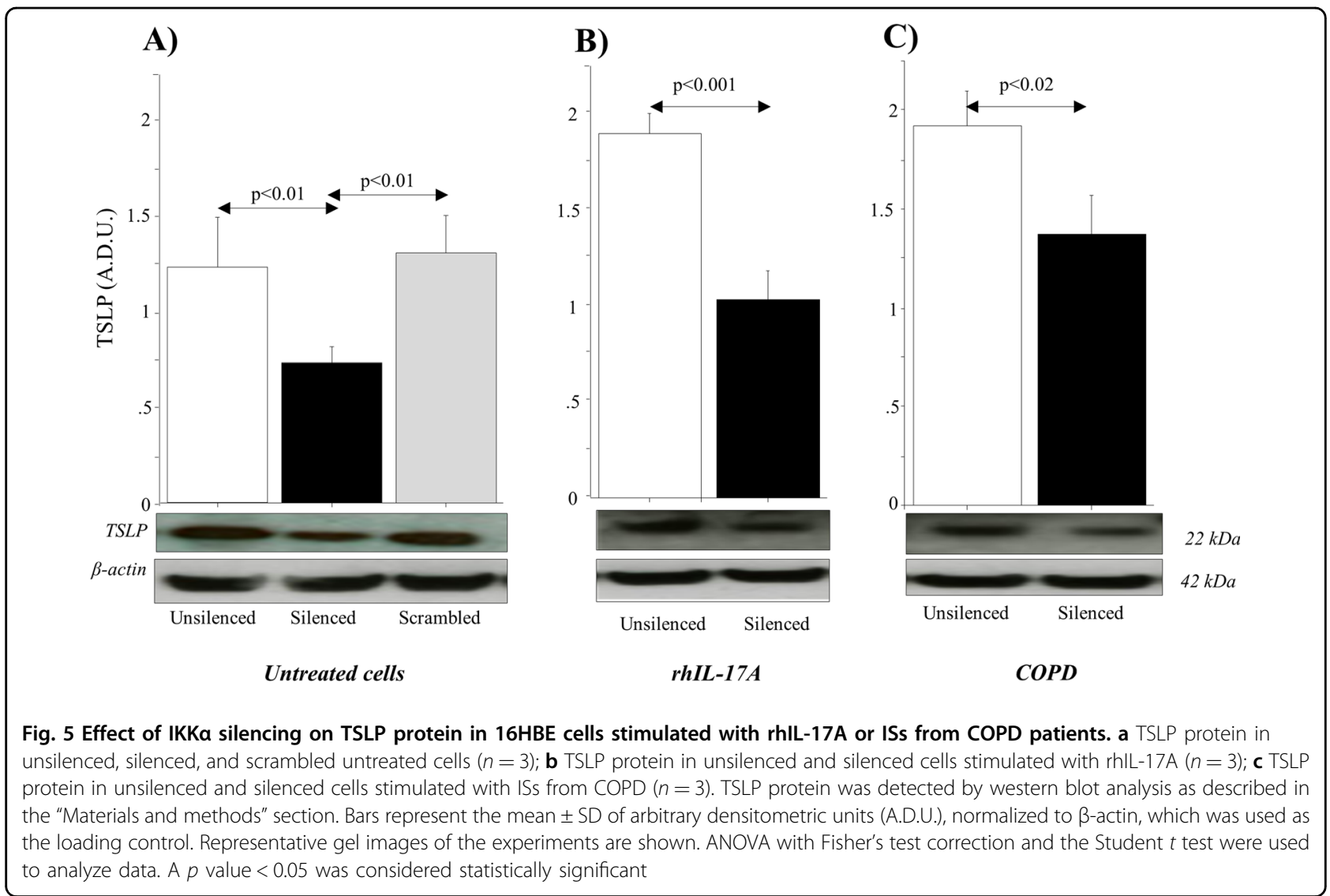

most adapted responses within the airway epithelium. Dysregulation of airway epithelial cell function contributes to the pathogenesis of major chronic inflammatory diseases of the lung, such as COPD, and the assessment of epithelial abnormalities includes phenotypic characteristics often associated with predicting a clinical benefit for epithelial-directed therapies ${ }^{23}$. TSLP is expressed predominantly by the epithelial cells of the lung $^{24,25}$. TSLP mRNA and protein are elevated in asthma and COPD; however, its role in COPD is not yet well understood $^{26}$. IL-17A has been found to be increased in submucosal biopsy specimens obtained from the large airways of COPD patients compared with control subjects $^{27}$, and it is believed to be involved in epithelial cell activation $^{28}$. On the other hand, Th17 immunity and the related cytokine IL-17A are involved in both innate and adaptive aspects of airway immunity, possibly representing a crucial cross-talk between the immune system and structural cells ${ }^{29,30}$. In our study, we detected higher levels of TSLP and IL-17A in the ISs from COPD patients and HS than in ISs from HC. These findings suggest a possible cross-talk between IL-17A found in the ISs and the activation of the bronchial epithelial cells that causes them to release TSLP during airway inflammation in COPD patients.
Differentiated cell cultures are an invaluable model for understanding the physiological properties of the human airway epithelium. Interactions between airway epithelium and environmental and inflammatory stimuli have been studied extensively in cell culture models of transformed $16 \mathrm{HBE}$ cell lines ${ }^{13,28,30}$. We studied the role of IL-17A in TSLP production in a $16 \mathrm{HBE}$ cell line stimulated with ISs from COPD, HS, and HC subjects, and our results show an increase in TSLP production in 16HBE cells stimulated with ISs from COPD subjects compared with cells treated with ISs from $\mathrm{HC}$ or untreated cells. Furthermore, we discovered that rhIL-17A increased TSLP production in $16 \mathrm{HBE}$ cells. We studied the effects of IL-17A depletion (anti-IL-17A Ab) in ISs from COPD on TSLP production in $16 \mathrm{HBE}$ cells and found a significant reduction of the production of TSLP mRNA transcripts and protein in 16HBE cells compared with cells stimulated with undepleted ISs. These findings highlight a direct and specific correlation between IL-17A and TSLP in the airways and show the involvement of IL-17A in the activation of bronchial epithelial cells that results in the release of TSLP during the inflammatory process of COPD. The validity and significance of these results are further supported by the data obtained from the experiments performed with normal bronchial epithelial. 


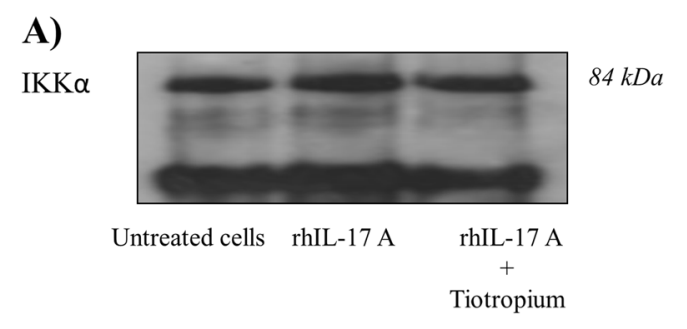

B)

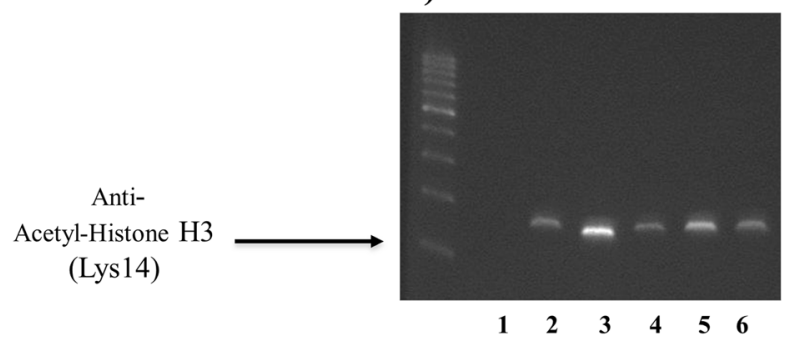

C)

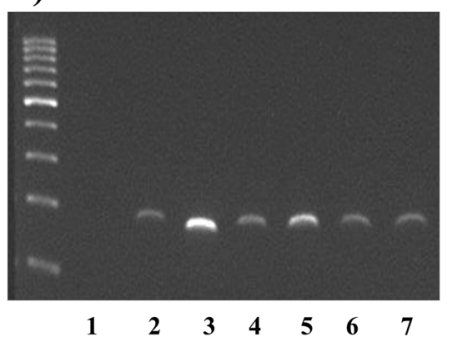

Fig. 6 IKKa binding to acetyl-His H3 (Lys14) and acting on the promoter region of TSLP in epithelial cells. a Coimmunoprecipitation of IKKa and Ac-His H3 (Lys 14) was performed in cell extracts from $16 \mathrm{HBE}$ cells stimulated for $4 \mathrm{~h}$ with rhlL-17A (20 ng/ml) in the presence or absence of tiotropium $(n=3)$. ChiP assay was performed using primers spanning the His H3 binding site of the human TSLP gene promoter: primer 1: $5^{\prime}-3^{\prime}$; primer $2: 3^{\prime}-5^{\prime} ; \mathbf{b}$ the cells were stimulated with rhIL-17A $(20 \mathrm{ng} / \mathrm{ml})$, alone or in combination, for $4 \mathrm{~h}$. Lane 1 : negative control of PCR; lane 2: negative control of immunoprecipitation; lane 3: positive control of PCR; lane 4: untreated cells; lane 5: rhIL-17A (20 ng/ml); lane 6, rhlL-17A + tiotropium ( $n=$ 3). $\mathbf{c}$ the cells were stimulated with ISs alone or in combination for $4 \mathrm{~h}$. Lane 1: negative control of PCR; lane 2: negative control of immunoprecipitation; lane 3: positive control of PCR; lane 4: untreated cells; lane 5: ISs from COPD patients; lane 6: ISs from COPD patients + tiotropium; line 7: ISs from COPD patients treated with anti-IL-17A Ab. Purified DNA was analyzed by PCR, using control primers specific for the GAPDH promoter. Representative gel images of the experiments are shown

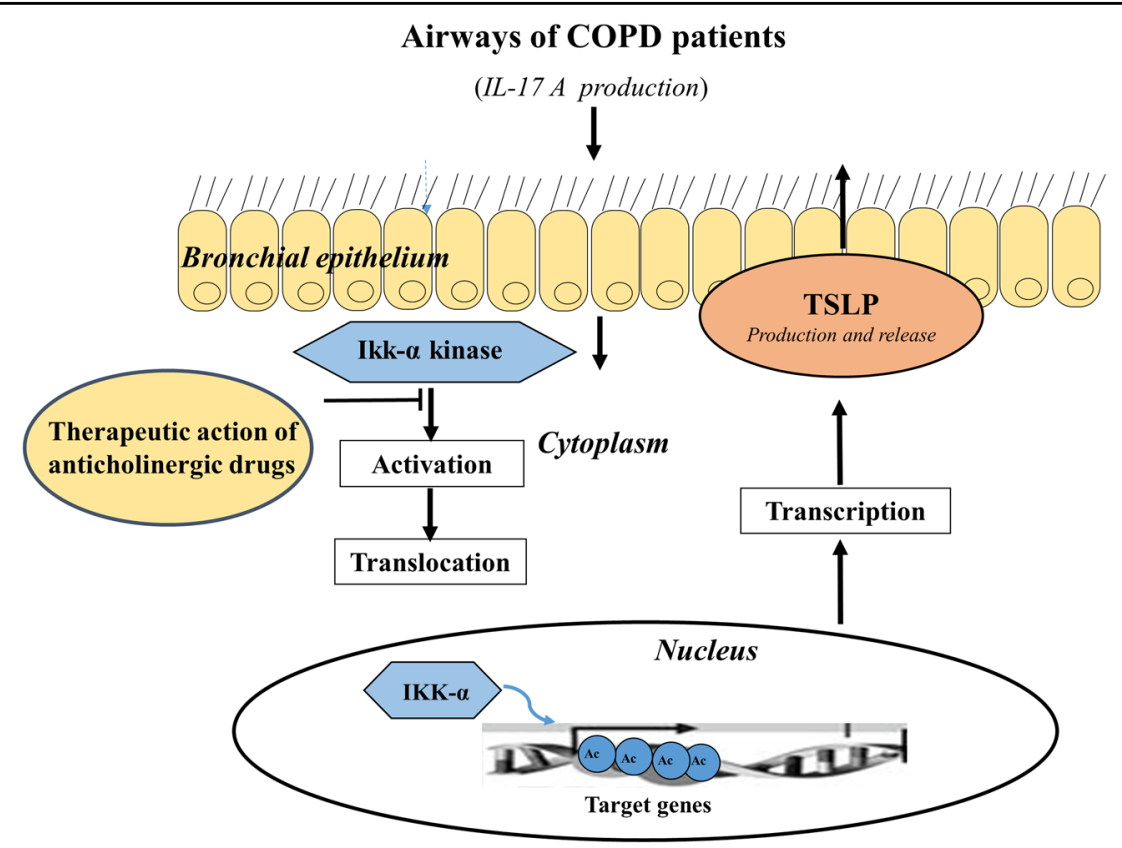

Fig. 7 Graphical abstract. Summary of the study

A thorough knowledge of the molecular mechanisms of epigenetic changes in abnormal lung inflammation is important to fully understand the pathophysiology of COPD and may lead to the development of novel epigenetic therapies in the near future ${ }^{31}$. Chromatin modifications due to histone $\mathrm{H} 3$ acetylation in lysine $(\mathrm{k} 9$, K14, K27) lead to sustained proinflammatory gene transcription through different molecules. Such modifications 
facilitate the access of the transcription complex on the promoter gene ${ }^{32}$. IкB kinase (IKK)/NF- $\kappa B$ family signaling mediates the expression of hundreds of genes involved in inflammation, immune response, cell survival, and can$\operatorname{cer}^{33,34}$. The IKK complex contains two kinase subunits, $\mathrm{IKK} \alpha$ and IKK $\beta$. ІкB kinase-driven nuclear factor- $\mathrm{KB}$ activation was observed in patients with asthma and COPD, and IKK $\alpha$ activity was higher in patients with COPD than in asthmatic patients ${ }^{35}$. Although IKK $\beta$ is predominantly cytoplasmic, IKK $\alpha$ has been found to shuttle between the cytoplasm and the nucleus and exert its functions as a chromatin kinase and acetylase, causing specific modifications of histones to generate expression of different genes in response to inflammatory stimuli ${ }^{36}$. Cigarette smoke-/TNF $\alpha$ as well as IL-17A induced the acetylation of histone $\mathrm{H} 3$ (K9) and inflammation via the differential activation of IKK $\alpha$ in human lung epithelial cells $^{20,37}$. In our in vitro model of IL-17A mediated COPD inflammation, we found that IKK $\alpha$ silencing reduced TSLP synthesis in 16HBE cells stimulated with rhIL-17A or with ISs from COPD patients compared with the stimulated and unsilenced cells. These findings support the role of IKK $\alpha$ in the synthesis of TSLP through an IL-17Amediated pathway in the airway epithelium of COPD patients. Finally, when the cellular extracts from 16HBE cells were co-immunoprecipitated with anti-acetyl-His H3 (Lys14) Ab and detected with anti-IKK $\alpha$, higher levels of IKK $\alpha$ were found in stimulated $16 \mathrm{HBE}$ cells than in cells that were untreated or treated with an anticholinergic drug (Tiotropium). Additionally, a ChiP assay showed that the histone acetylated in Lys14 bound to the TSLP promoter region in cells stimulated with rhIL-17A or with ISs from COPD subjects. Depletion of IL-17A in ISs from COPD patients or epithelial cell treatment with tiotropium reduced this effect. These findings suggest that IL-17A found in the airways of COPD patients could potentially activate the synthesis of TSLP, inducing epigenetic chromatin remodeling in bronchial epithelial cells associated with IKKa acetylation of histone H3 at Lys14. We suggest that the anticholinergic drugs could represent a therapeutic approach that regulates the chromatin remodeling involved in the activation of inflammatory genes, such as TSLP, through IKK $\alpha$ acetylation of histone $\mathrm{H} 3$ at Lys14 in the airways of COPD patients. We previously reported that IL-17A in the airways of COPD patients induces chromatin remodeling and promotes the release of IL-8 in the bronchial epithelium and that anticholinergic drugs are able to control this proinflammatory activity ${ }^{20}$. For the present study, we used the same experimental ex vivo/in vitro model to study TSLP; however, we recruited a different number of $\mathrm{HC}$ subjects (10 rather than 14) and COPD patients (12 rather than 16) than for our previous study ${ }^{20}$. Furthermore, although the two studies appear to be similar, the current study showed that IL-17A-associated IKK- $\alpha$ signaling induced TSLP production by histone $\mathrm{H} 3$ acetylation at Lys14 in epithelial cells, rather than IL-8 production by histone H3 acetylation at Lys $9^{20}$. Finally, further studies are necessary to investigate the direct or indirect effects of IL-17A on IKKa signaling involved in IL-8 or TSLP production in bronchial epithelial cells.

The inhaled concentration of anticholinergic tiotropium is an 18- $\mu \mathrm{g}$ dose once-daily medication for COPD. It decreased rapidly in a multi-compartment manner as previously described ${ }^{38,39}$. Steady-state trough plasma concentrations were very low values $(3-4 \mathrm{pg} / \mathrm{mL})$. However, following treatment of the patients with a single 18$\mu \mathrm{g}$ dose once per day, the overall concentration of tiotropium in the lungs is uncertain, and the physiologic concentration is unknown. For these reasons, we chose to use a tiotropium concentration of $100 \mathrm{nM}$, as it is commonly used in "in vitro" bronchial epithelial cell studies $^{20,39,40}$.

In conclusion, our results contribute to a better understanding of the chromatin-mediated remodeling mechanisms associated with Th17 immunity and TSLP production in the airways of COPD patients, supporting the relevance of the role of chromatin modifications and deacetylases in COPD-induced lung inflammation ${ }^{32}$. Th17 immunity regulates the activation of TSLP production in bronchial epithelial cells, representing a key regulator of COPD pathogenesis. These data open up a new perspective on the importance of TSLP as a potential therapeutic target of anticholinergic drugs in COPD. Anticholinergic drugs showed a potential antiinflammatory effect that might represent a useful innovative and alternative therapy to control IL-17A-induced production of mediators in epithelial cell derived from COPD patients. However, we recommend investigating the aforementioned mechanism in a larger population of COPD subjects and promoting adequate clinical trials to confirm the relevant contribution of anticholinergic drug therapy to controlling TSLP production in the airways.

\section{Acknowledgements}

We wish to remember and thank the late Dr. Liboria Siena, who obtained RTPCR data. The study was supported by an unrestricted educational grant from Boehringer Ingelheim Pharma GmbH \& Co. KG (Contract number: 43028659).

\footnotetext{
Author details

"Institute of Biomedicine and Molecular Immunology "A. Monroy" (IBIM), National Research Council of Italy (CNR), Palermo, Italy. 'Dipartimento di Biomedicina sperimentale e Neuroscienze Cliniche (BioNec), University of Palermo, Palermo, Italy. ${ }^{3}$ Interventional Pulmonology Unit, La Maddalena Cancer Center, Palermo, Italy
}

\section{Author contributions}

The authors GA and MP conceived the study and designed the experiments. $A B, L R, R G, G D A, A M M$, and MM performed the technical procedures. MP provided the interpretation of data and wrote the manuscript. FB and RG revised the final draft of the manuscript. All authors read and approved the final version of the manuscript. 


\section{Conflict of interest}

The authors declare that they have no conflict of interest.

\section{Publisher's note}

Springer Nature remains neutral with regard to jurisdictional claims in published maps and institutional affiliations.

Received: 29 March 2018 Revised: 12 June 2018 Accepted: 21 June 2018. Published online: 5 October 2018

\section{References}

1. Barnes, P. J. Immunology of asthma and chronic obstructive pulmonary disease. Nat. Rev. Immunol. 8, 183-192 (2008).

2. Barnes, P. J. Future treatments for chronic obstructive pulmonary disease and its comorbidities. Proc. Am. Thorac. Soc. 8, 857-864 (2008).

3. Johnson, $\mathbf{M}$. Interactions between corticosteroids and beta2-agonists in asthma and chronic obstructive pulmonary disease. Proc. Am. Thorac. Soc. 3 200-206 (2004).

4. Belmonte, K. E. Cholinergic pathways in the lungs and anticholinergic therapy for chronic obstructive pulmonary disease. Proc. Am. Thorac. Soc. 4, 297-304 (2005).

5. Meurs, H., Oenema, T. A., Kistemaker, L. E. \& Gosens, R. A new perspective on muscarinic receptor antagonism in obstructive airways diseases. Curr. Opin. Pharmacol. 3, 316-323 (2013).

6. Bateman, E. D. et al. Alternative mechanisms for tiotropium. Pulm. Pharmacol. Ther. 22, 533-542 (2009).

7. Profita, M. et al. Smoke, choline acetyltransferase, muscarinic receptors, and fibroblast proliferation in chronic obstructive pulmonary disease. J. Pharmacol. Exp. Ther. 2, 753-763 (2009).

8. Barnes, P. J. Role of HDAC2 in the pathophysiology of COPD. Annu. Rev. Physiol. 71, 451-464 (2009).

9. Barnes, P. J., Adcock, I. M. \& Ito, K. Histone acetylation and deacetylation: importance in inflammatory lung diseases. Eur. Respir. J. 25, 552-563 (2005).

10. Hart, L. A., Krishnan, V. L., Adcock, I. M., Barnes, P. J. \& Chung, K. F. Activation and localization of transcription factor, nuclear factor-kappaB, in asthma. Am. J. Respir. Crit. Care. Med. 158, 1585-1592 (1998).

11. Yamamoto, Y., Verma, U. N., Prajapati, S., Kwak, Y. T. \& Gaynor, R. B. Histone H3 phosphorylation by IKK-alpha is critical for cytokine-induced gene expression. Nature 5, 655-659 (2003).

12. Ouyang, W., Kolls, J. K. \& Zheng, Y. The biological functions of T helper 17 cell effector cytokines in inflammation. Immunity 28, 454-467 (2008).

13. Zijlstra, G. J., Ten Hacken, N. H., Hoffmann, R. F., van Oosterhout, A. J. \& Heijink, I. $\mathrm{H}$. Interleukin-17A induces glucocorticoid insensitivity in human bronchial epithelial cells. Eur. Respir. J. 2, 439-445 (2012).

14. Wong, C. K., Cao, J., Yin, Y. B. \& Lam, C. W. Interleukin-17A activation on bronchial epithelium and basophils: a novel inflammatory mechanism. Eur. Respir. J. 4, 883-893 (2010).

15. $\mathrm{Wu}$, J. et al. Thymic stromal lymphopoietin promotes asthmatic airway remodelling in human lung fibroblast cells through STAT3 signalling pathway. CellBiochemFunct 6, 496-503 (2013).

16. Verstraete, $\mathrm{K}$. et al. Structure and antagonism of the receptor complex mediated by human TSLP in allergy and asthma. Nat. Commun. 8, 14937 (2017).

17. Redhu, N. S. \& Gounni, A. S. Function and mechanisms of TSLP/TSLPR complex in asthma and COPD. Clin. Exp. Allergy 7, 994-1005 (2012).

18. Caramori, G., Adcock, I. M., Di Stefano, A. \& Chung, K. F. Cytokine inhibition in the treatment of COPD. Int. J. Chron. Obstruct. Pulmon. Dis. 9, 397-412 (2014).

19. Pauwels, R. A., Buist, A. S., Calverley, P. M., Jenkins, C. R. \& Hurd, S. S. GOLD Scientific Committee, Global strategy for the diagnosis, management, and prevention of chronic obstructive pulmonary disease. NHLBIMHO Global Initiative for Chronic Obstructive Lung Disease (GOLD) Workshop summary. Am. J. Respir. Crit. Care. Med. 5, 1256-1276 (2001).

20. Anzalone, G. et al. IL-17A induces chromatin remodeling promoting IL-8 release in bronchial epithelial cells: effect of Tiotropium. Life Sci. 152, 107-116 (2016).

21. Crystal, R. G., Randell, S. H., Engelhardt, J. F., Voynow, J. \& Sunday, M. E. Airway epithelial cells: current concepts and challenges. Proc. Am. Thorac. Soc. 7, 772-777 (2008)

22. Knight, D. A. \& Holgate, S. T. The airway epithelium: structural and functional properties in health and disease. Respirology 4, 432-446 (2003).

23. Gras, D., Chanez, P., Vachier, l., Petit, A. \& Bourdin, A. Bronchial epithelium as a target for innovativetreatments in asthma. Pharmacol. Ther. 3, 290-305 (2013).

24. Allakhverdi, Z. et al. Thymic stromal lymphopoietin is released by human epithelial cells in response to microbes, trauma, or inflammation and potently activates mast cells. J. Exp. Med. 2, 253-258 (2007).

25. Liu, Y. J. et al. TSLP: an epithelial cell cytokine that regulates $T$ cell differentiation by conditioning dendritic cell maturation. Annu. Rev. Immunol. 25, 193-219 (2007).

26. Ying, S. et al. Expression and cellular provenance of thymic stromal lymphopoietin and chemokines in patients with severe asthma and chronic obstructive pulmonary disease. J. Immunol. 4, 2790-2798 (2008).

27. Di Stefano, A. et al. T helper type 17-related cytokine expression isincreased in the bronchial mucosa of stable chronic obstructive pulmonary disease patients. Clin. Explmmunol. 2, 316-324 (2009).

28. Kawaguchi, M. et al. Modulation of bronchial epithelial cells by IL-17. J. Allergy Clin. Immunol. 5, 804-809 (2001).

29. Hung, L. Y., Velichko, S., Huang, F., Thai \& Wu, R. Regulation of airway innate and adaptive immune responses: the IL-17 paradigm. Crit. Rev. Immunol. 4, 269-279 (2008).

30. Montalbano, A. M. et al. Cigarette smoke affects IL-17A, IL-17F and IL-17 receptor expression in the lung tissue: Ex vivo and in vitro studies. Cytokine $\mathbf{2}$, 391-402 (2015).

31. Comer, B. S., Ba, M., Singer, C. A. \& Gerthoffer, W. T. Epigenetic targets for novel therapies of lung diseases. Pharmacol. Ther. 147, 91-110 (2015).

32. Rajendrasozhan, S., Yao, H. \& Rahman, I. Current perspectives on role of chromatin modifications and deacetylases in lung inflammation in COPD. COPD 4, 291-297 (2009)

33. Gilmore, T. D. Introduction to NF-kappaB: players, pathways, perspectives. Oncogene 51, 6680-6684 (2006).

34. Hayden, M. S. \& Ghosh, S. Shared principles in NF-kappaB signaling. Cell 3, 344-362 (2008).

35. Gagliardo, R. et al. IKB kinase-driven nuclear factor-kB activation in patients with asthma and chronic obstructive pulmonary disease. J. Allergy Clin Immunol. 3, 635-645 (2011).

36. Huang, W. C. \& Hung, M. C. Beyond NF-kB activation: nuclear functions of $1 \mathrm{kB}$ kinase a. J. Biomed. Sci. 20, 3 (2013).

37. Chung, S. et al. NF-KB inducing kinase, NIK mediates cigarette smoke/TNFainduced histone acetylation and inflammation through differential activation of IKKS. PLOS ONE 8, e23488 (2011).

38. Durham, M. C. Tiotropium (Spiriva): a once-daily inhaled anticholinergic medication for chronic obstructive pulmonary disease. Proc. (Bayl. Univ. Med. Cent.). 17, 366-373 (2004).

39. $L u, J$. J. et al. The activation of M3 mAChR in airway epithelial cells promotes IL8 and TGF- $\beta 1$ secretion and airway smooth muscle cell migration. Respir. Res. 17, 25 (2016).

40. Yamaya, M. et al. Inhibitory effects of tiotropium on rhinovirus infection in human airway epithelial cells. Eur. Respir. J. 40, 122-132 (2012). 